\title{
La bibliografía de las bibliografías jesuíticas en los ámbitos hispánicos (1773-1990)
}

The bibliography of the jesuíticas bibliographies in the Hispanic scopes (1773-1990)

José del Rey Fajardo SJ* DOI: http://dx.doi.org/10.31057/2314.3908.v6.n2.22957

Resumen: La historiografía es una ciencia del Renacimiento y consiste en detectar la bibliografía de las bibliografías desarrolladas por una institución dedicada a las letras, las ciencias y las artes. El presente estudio se centra en la visión jesuítica de la bibliografía de las bibliografías desarrollas en el mundo hispánico desde 1773 hasta 1999 ya que se convierte en la carta de navegar para poder interpretar ese complicado mundo.

Palabras claves: Historiografía. Compañía de Jesús. Mundo hispánico: 1773-1999.

\begin{abstract}
The historiography is a science of the Renaissance and consists of detecting the bibliography of the bibliographies developed by an institution dedicated to letters, sciences and arts. The present study focuses on the Jesuit vision of the bibliography of the bibliographies developed in the Hispanic world from 1773 to 1999, since it becomes the navigational chart for interpreting this complicated world.
\end{abstract}

Keywords: Historiography. Jesus company. Hispanic World: 1773-1999.

Recibido: 21 de agosto de 2018.

* Universidad Católica “Andrés Bello”. Caracas. E-mail: jfajardo1934@gmail.com

77 José del Rey Fajardo SJ. La bibliografía de las bibliografías jesuíticas ... 77-98. 
Evaluado: 14 de noviembre de 2018.

En el presente trabajo nos centraremos en la acción de los jesuitas españoles y americanos y en su preocupación por la ciencia bibliográfica en su proyección hispánica.

Tras el trauma que supuso la pérdida de la nacionalidad española y su consiguiente extrañamiento de la geografía hispana y americana en 1767, y el desencanto generado por la muerte legal de la Orden en 1773, signada por el breve papal Dominus ac Redemptor, pocos pensaron que la reacción cultural e intelectual de los exjesuitas alcanzaría los niveles que los expulsos trataron de recoger para legarlos a la posteridad y a la historia.

Pero viniendo al caso que nos ocupa como es el de la acción de los jesuitas españoles y americanos y su preocupación por la ciencia bibliográfica, tanto de la universal Compañía, como sobre todo de sus raíces inmediatas, era lógico que la memoria histórica se redujera a la Provincia jesuítica a la que habían servido, pues constituía el mejor modo de ser fieles a una identidad que habían elegido libremente.

La investigación moderna está tratando de recuperar esos pasos perdidos ${ }^{1}$ y en el caso de los expatriados españoles y americanos, desde 1773, se puede seguir su ritmo de producción, en parte, gracias a las huellas dejadas en la industria editorial de la Romagna (Bellettini, 1998, pp. 557-657).

Algunos hombres de aquellas generaciones intuyeron el valor de la memoria histórica de 5.000 jesuitas expatriados de los reinos de España en 1767 y arrojados como indeseables a los Estados Pontificios y la respuesta intelectual y cultural que dieron los perseguidos (Domergue, 2001, pp. 265-294) frente a sus perseguidores ${ }^{2}$. Con toda razón afirma Miguel Batllori (1966, p. 590) que: "gracias a la colaboración de los exiliados hispano-portugueses, Italia llegó a ser, en el último cuarto del siglo XVIII, el centro más denso de todo el americanismo europeo".

Dentro de la Compañía de Jesús, que muere en 1773, existía un género literario que fue vital en su memoria histórica: los "Diarios" que cada casa debía elaborar para cumplir con una exigencia tradicional como era la denominada "historia domus" y el informe general de la Provincia que solía reducirse a las llamadas "Cartas Annuas". Dentro de la producción escrita entre los años 1767 y 1815 se están reivindicando los "manuscritos de exilio" (Fernández Arrillaga, 2002, pp, 494-511, Page, 2011). Pero sin lugar a dudas el que se ha constituido en el auxilio permanente de los investigadores de esta difícil época es el Diario $^{3}$ del P. Manuel Luengo (1735-1816) (Olaechea, 2001, III, p. 2.437) pues la obra de este jesuita castellano se puede afirmar que es el mejor observatorio de la vida de los españoles y americanos en tierras italianas ya que recoge la cotidianidad de sus correligionarios con una constancia y devoción casi benedictinas.

\footnotetext{
${ }^{1}$ Es imposible resumir la literatura bibliográfica producida. Nos remitimos a Tieltz, 2001. También un equipo de investigadores de la Universidad de Alicante han ido publicando importantes aportes: Giménez López, 1997 y 2002.

${ }^{2}$ Una interesante visión sobre el tema la ofrece Astorgano Abajo, 2004, pp. 171-268.

${ }^{3}$ Manuel Luengo SJ: "Diario, sobre el destierro y vicisitudes de la Provincia de Castilla la Viexa, después más en general de toda la Compañía, aunque siempre con mayor particularidad de la dicha Provincia de Castilla". Manuscrito que reposa en el Archivo de Loyola (Guipúzcoa); consta de 63 tomos (falta el tomo IV correspondiente al año 1770). Ha sido publicado el tomo I por la investigadora de la Universidad de Alicante Inmaculada Fernández Arrillaga.
} 
Gracias a este discutido "Diario" podemos reconstruir una buena parte de la historiografía jesuítica en el exilio.

No hubo que esperar mucho tiempo para que surgieran ideas y acciones a fin de poder recoger tanto esfuerzo, al parecer escondido e inédito, tanto de las Provincias como de toda la Asistencia de España.

De muy diversas formas y métodos compitieron las Provincias hispanoamericanas en no dejar morir su historia.

Podemos comenzar con la obra de Onofre Pratdesaba (1733-1810) (Batllori, 2001, IV, pp. 3.214-3.215.) pues como neohumanista e historiador dedicó una buena parte de su interés científico a las labores bibliográficas. En 1787 publicaba en Ferrara su Vicennalia sacra aragoniensa sobre 20 jesuitas aragoneses fallecidos entre 1767 y 1787. Según Sommervogel (1890, VI, p. 1.173) el propio autor comenzó una continuación de esta obra de acuerdo con el manuscrito encontrado en el colegio de Ferrara, en $1853^{4}$, por el P. Pablo Beorchia (1795-1859) (Sommervogel, 1890, I, pp.1.317-1.318). En 1803 sacaba a la luz, con el seudónimo de José Fontdevall el Indice de escritores aragones.

Pero también su preocupación se extendió al resto de las provincias hispano americanas y dejó dos volúmenes manuscritos que fueron de gran ayuda a Diosdado Caballero en la redacción de sus Suplementos que llevaban por título Annus faustus (Batllori, 2001, IV , 3.215). Al parecer se sirvió en la redacción de esta nueva obra de un manuscrito de un tal Rafael Sandoval, amigo de Diosdado Caballero (Sommervogel, 1890, IV, p. 1.174). De su aporte a la historiografía americana hablaremos más adelante.

Muy significativo nos parece el caso del P. Bernardo Recio (1714-1791) (Villalba, 2001, IV, p. 3.304 y García Goldáraz, 1947, pp. 21-45), quien cuando se desempeñaba como Procurador de la Provincia de Quito fue detenido en Figueras (Gerona) el 11 de marzo de 1767, víctima de una acción burda de las que a veces montan las policías inescrupulosas. Hecho preso en el convento de la Merced de Gerona redactó la Compendiosa relación de la cristiandad de Quito, en cuyo tomo tercero intercaló el Catálogo de escritores catalanes de la Compañía que prosiguió en Roma hasta el año $1785^{5}$.

Aunque no es nuestro deseo multiplicar la presencia de los inéditos en esta breve reseña, sin embargo, pensamos que no debe excluirse a Mateo Aymerich (1715-1799) (Batllori, 2001, I, pp. 311-312. Martínez de la Escalera, 1982, pp. 283-289. Uriarte y Lecina, 1929, I, pp. 387-392) pues, en una carta que le dirige Francisco Javier Llampillas (Génova, 5 de mayo de 1781) le hace presente que "ninguno mejor que V. puede suministrarle [al P. Zaccaria] las noticias tocantes a nuestra Provincia [de Aragón] ${ }^{6}$ aunque sus notas se extendían a la Península Ibérica y a tierras americanas (Uriarte-Lecina, 1929, p, 391).

\footnotetext{
4 "Noticias que se han adquirido después de la impresión del P. Onofrio Prat de Saba de personas fidedignas que han visto por si mesmas lo que cada una de ellas depone, pertenecientes a la vida y costumbres de los Sujetos de la Provincia de Aragon de la Compañía de Jesús, que fallecieron gloriosamente después de su estrañamiento. Cuyo indice se pone más abajo. Año 1788, 134 pp.”. Este manuscrito contiene 37 noticias de las que las 23 primeras pertenecen al P. Prat.

${ }^{5}$ Apareció en el tomo 3 de su obra: Compendiosa relación de la cristiandad de Quito, pp., 215-251. Véase: Lecina, 1916, I, p. LIX.

${ }^{6}$ Extracto de la carta puede verse en Uriarte-Lecina, 1929, I, p. LVI.
} 
La Provincia de Andalucía tuvo su cronista en el publicista y critico Juan de Osuna (1745-1818) (Borja Medina, 2001, III, pp. 2.931-2.932). Fue un prolífico escritor desde su destierro de Italia (Sommervogel, 1894, V, pp. 1.978-1.980), sin embargo no es fácil clarificar su obra bibliográfica sobre la Compañía. Según Borja Medina escribió De Baeticis scriptoribus qui per hos triginta annos [1768-1798] rem litterariam apud Italos illustrarunt. Pensamos que se trata del libro VII de su obra De Baetica Societate Jesu apud Italos exulante Commentaria (Borja Medina, 2001, IV, p. 2.932). Como hasta el momento no han podido encontrarse algunos manuscritos de los que se tienen referencias indirectas, no podemos llegar al conocimiento exacto de obras como: De Hispanis qui in Italia libros ediderunt ab anno 1768. Y nos preguntamos: ¿Será ésta la misma que Lecina señala como: Memoria sobre los escritores españoles que han impreso en Italia, desde 1768 hasta el 1788 (Lecina, 1929, I, p. LVIII ) ${ }^{7}$ ?

Todavía más oscura se nos presenta la producción bibliográfica del conocido crítico antijansenista Francisco Gustá (1744-1816) (Batllori, 2001, II, pp. 1.851-1.852). Miembro de la gran generación de jesuitas aragoneses en el destierro italiano, había estudiado a lo largo de su carrera en España con Juan Francisco Masdeu, Pedro Montengón, Mateo Aymerich y Juan Andrés. Escribió un estudio, al parecer, bastante extenso pues comprendía un universo de más de 400 autores $^{8}$. En la elaboración de esta investigación contó con la ayuda del P. Luis María Rezzi (1785-1857), curioso amigo de Gustá que fue expulsado de la Compañía por sus ideas peregrinas en la Congregación General y posteriormente fue el director de la biblioteca de Corsini (Sommervogel, 1895, VI, pp. 1.701-1.702).

Mas nuestro principal propósito se centra en la formación de la historia de la historiografía hispanoamericana que nace como disciplina independiente en esos aciagos años.

Ya el P. Manuel Luengo en dos ocasiones, al menos, habla de la necesidad de componer una Biblioteca que recogiese la producción literaria jesuítica. En 1778 sugiere la posibilidad de tal publicación (Luengo, XII (Año 1778, pp. 352-433) en la pugna literaria entablada entre los hijos de San Ignacio hispanos y los italianos, en el marco de la polémica suscitada entre Tomás Serrano (1715-1784)", Juan Andrés (1740-1817) y Francisco Javier Llampillas (1731-1810) (Batllori, 2001, IV, p. 3.560, I, pp. 163-165 y III, p. 2.400) con Javier Bettinelli (1718-1808) y Girolamo Tiraboschi (1731-1794) (Zanfredini, 2001, I, p. 432 y IV, pp. 3.804-3.805) pues estos últimos defendían que los escritores hispano-latinos representaban la decadencia de la latinidad. La segunda data de 1790, época en que los jesuitas españoles han ofrecido al público europeo su mejor producción intelectual, y esos resultados le despiertan el deseo trasmitir a la posteridad el conocimiento de tan magna obra (Luengo, XXIX (Año 1790), pp. 247-265).

Pero la figura principal de esta tarea científica para los hombres de la lengua castellana se centra en la obra del P. Lorenzo Hervás y Panduro (1735-1809) (De la Campa, 2001, II, pp. 1.914-1.916) ${ }^{9}$ protagonista indiscutible de todo este gigantesco proyecto.

\footnotetext{
${ }^{7}$ Lecina cita el texto de Hervás, 1778, I, p. 137.

${ }^{8}$ Notizia degli Scrittori Gesuiti, i quali dopo l'abolizione della Compagina hanno publicato diverse opere. Según Diosdado Caballero (Bibliotecae scriptorum Societatis Jesu suplementa. Romae, II (1816) 46, en su escrito se recensan 200 italianos, 131 españoles, 12 portugueses, 47 franceses, 29 alemanes, ingleses y polacos 6 .

${ }^{9}$ A este artículo nos remitimos para su extensa bibliografía.
} 
Hervás no indica ni cuándo concibió la idea de la Biblioteca ni la fecha exacta de su composición, pero en 1793 había concluido su primera redacción; con todas sus adiciones continuas nos hacen llegar al 1799, según se desprende de la lectura del propio texto (Astorgano Abajo, 2004, pp. 178-182).

Así surgió la Biblioteca jesuítico-española de escritores, que han florecido [poren] siete lustros. Estos empiezan desde el año 1759, principio del reinado del augusto rei Carlos III, y acaban en el año $1793^{10}$, manuscrito que reposa en el Archivo de Loyola (Guipúzcoa) ${ }^{11}$.

El manuscrito consta de dos volúmenes. En el primero se encuentra el Catálogo $1^{\circ}$, es decir, el que contiene los escritores con obra impresa ${ }^{12}$. El volumen segundo recoge: el Catálogo $2^{\circ}$ : Escritores jesuitas españoles y americanos que dentro del mismo plazo escribieron sus obras, pero dejándolas inéditas ${ }^{13}$; catálogo $3^{\circ}$. Escritores jesuitas portugueses que imprimieron o dejaron inédita alguna obra durante los años de su destierro $^{14}$; catálogo $4^{\circ}$. Escritores jesuitas de obras impresas o inéditas, extranjeros, pero que, domiciliados en España, murieron antes de 1767 o salieron extrañados con los españoles ${ }^{15}$. Además incluye el autor dos Apéndices: en primero reune el "Catálogo de manuscritos de escritores españoles y portugueses existentes en siete bibliotecas insignes de Roma" españolas hai en las Bibliotecas de Roma"17. Y concluye con el "Indice de los nombres y personas, y de cosas notables, que se citan en los antecedentes catálogos de las Bibliotecas Romanas, Angélica, Barberini, Casanatense, Corsini, Jesuítica, Vallicellana y Zelada" ${ }^{\prime 18}$.

En total 495 retratos bio-bibliográficos y la descripción de 808 manuscritos (Apéndice, 1) y 9 manuscritos de la Colección canónico-española (Apéndice, 2) ${ }^{19}$. Y frente a la Bibliothèque de Sommervogel, Astorgano contrapone 325 escritores del jesuita francés, frente a los 495 de Hervás, es decir, que el español incluye 170 entradas nuevas (Astorgano Abajo, 2004, p. 193-194). Y como es habitual en esta clase de obras

\footnotetext{
${ }^{10}$ Uriarte describe así el manuscrito en su Catálogo razonado, I, pag., XXV. Lorenzo Hervás y Panduro. Biblioteca jesuítico-española de escritores, que han florecido [por-en] siete lustros. Estos empiezan desde el año 1759, principio del reinado del augusto rei Carlos III, y acaban en el año 1793. Obra de Lorenzo Hervás y Panduro, etc. [Volumen primero. Volumen segundo, en el cual se contienen tres catálogos de escritores y noticia de los manuscritos que de escritores españoles hay en siete bibliotecas insignes de Roma]. Dos tomos en folio de 198 hojas ( $\sin 2$ de portada y advertencia), 231 (sin 9 de índices y final). Faltan los folios, 4, 5, 6 y 7, la introducción y la dedicatoria. De la introducción hace mención el autor en la introducción especial del $2^{\circ}$ tomo. De la introducción y dedicatoria habla una carta de Bernad aHervás, 13 de septiembre de 1799. Sin embargo, a juicio de Astorgano Abajo, quien ofrece la mejor descripción de la Biblioteca, es Enrique del Portillo (1912, p. 18).

${ }^{11}$ Archivo de Loyola. Caja, 06, $\mathrm{n}^{\mathrm{o}}$., 01. Para la descripción de los manuscritos y sus publicaciones parciales, véase: Astorgano Abajo, 2004, pp, 174-178.

${ }^{12}$ Consta de 199 folios.

${ }^{13}$ Volumen II, folios: 1-65v.

${ }^{14}$ Volumen, II, folios,: 66-86v.

${ }^{15}$ Volumen, II, folios: 87-92v.

${ }^{16}$ Volumen II. Apéndice I, folios: 93-201v.

${ }^{17}$ Volumen, II, Apéndice II, folios: 202-231v.

${ }^{18}$ Volumen II, folios: 232-238v.

${ }^{19}$ Véase: Astorgano Abajo, 2004, p. 172.
}

81 José del Rey Fajardo SJ. La bibliografía de las bibliografías jesuíticas ... 77-98. 
y con los medios que existían en el siglo XVIII, es natural que haya desconocido o no haya podido consultar algunos autores que recoge el editor de la Biblioteca jesuíticoespañola a punto de conocer la luz pública (Astorgano Abajo, 2004, p. 195-199).

Un elemento decisivo para la elaboración de la Biblioteca -amén de su peregrinar por las bibliotecas romanas e italianas- lo constituye el hecho de que Hervás supo mantener correspondencia con la mayoría de los "intelectuales jesuitas" que vivían en su misma situación de expatriados ${ }^{20}$ y de ellos obtuvo valiosísimas informaciones de primera mano, por ejemplo, en el ámbito de las lenguas indígenas y exóticas como se puede seguir en la lectura de su Idea dell'Universo y también el Catálogo de las Lenguas $^{21}$.

En definitiva esperamos que la publicación de la obra del jesuita conquense sirva para ilustrar obras similares como la nuestra.

El nombre del P. Andrés Artola (1818-1887) (Cacho, 2001, I, p. 255. Sommervogel, 1890, I, pp, 593-594 y Decorme1916, II, pp. 220-228; 340-348), también debe figurar en este pequeño ensayo pues fue un devoto de la bibliografía jesuítica y en especial la hispanoamericana. Mientras vivió en Loyola (Guipúzcoa) se apasionó por la obra escrita de los miembros de la Compañía de Jesús y se dedicó a entresacar de los Catálogos ya impresos los autores de las diversas Provincias de España e Indias, tarea que provenía del estudio de las bibliografías ya impresas, de los apuntes que quedaban en el Archivo Loyola, de los bibliógrafos del siglo XVIII, o de las bibliotecas que visitaba. De esta suerte nació su aporte a la Biblioteca de autores jesuitas hispanoamericanos $\left(\right.$ Artola, 1871) ${ }^{22}$. También dejó escritos Índices de autores de las siguientes provincias: Chile, 65 escritores; Filipinas, 106; México, 423; Paraguay, 111; Perú, 136; Quito, 70. A ellos hay que añadir otra lista de los jesuitas navarros que contabiliza 43 (UriarteLecina, 1929, I, p. LXVIII). Según Cacho (2001, I, p. 255) dejó inéditos quince volúmenes relativos a la bibliografía de los jesuitas españoles. Asimismo, de su estancia en tierras mexicanas hay que añadir el Catálogo de los jesuitas expulsados en 1767 (Artola, 1871).

Pero el gran continuador de Lorenzo Hervás y Panduro, con una visión holística de la Compañía de Jesús hispana y americana, fue el P. José Eugenio de Uriarte (18421909) (Martínez de la Escalera, 2001, IV, p. 3.861. Lecina, 1916, V, pp. XI-XXV. Pérez Goyena, 1916, pp. 384-387).

Cuando en 1874 -como él mismo confiesa- (Uriarte, 1904, I, pp. VII y ss.) tuvo la fortuna de tropezarse con gran parte de las memorias literarias que habían sido remitidas a Roma para continuar la Biblioteca de Sotuelo, así como gran parte de los artícu-

\footnotetext{
${ }^{20}$ Para una lista de amigos y corresponsales de Hervás, véase: Aatorgano Abajo, 2004, pp. 212-227.

${ }^{21}$ Hervás publicó su gran obra Idea dell'Universo, che contiene la Storia della vita dell'uomo, elementi cosmografici, viaggio estatico al mondo planetario, e Storia della terra. Cesena, 1778-1792, 22 volúmenes. Los tomos XVII-XXI salieron con título separado y son: XVII: Catalogo delle lingue conosciute e noticia della loro afinitá e diversità. 1784. XVIII: Origine, formazione, mecanismo ed armonia degl'idiomi. 1785. XIX: Arithmetica delle Nazioni, e divisione del tempo fra gli Orientali. 1786. XX. Vocabulario poliglotto..., 1787. XXI: Saggio prattico delle lingue come prolegomeni e una raccolta di orazioni dominicali in più de trecento lingue et dialecti..., 1787. Toda esta ingente obra fue refundida y considerablemente aumentada en su edición castellana (Véase: Sommervogel, 1890, IV, 319-322).

22 Tres tomos en cuarto. El tomo I lleva al frente: "Specimen Bibliothecae Hispano-Jesuiticae seu Syllabus Hispaniensium S. J. Scriptorum ex variis monumentis qua editis, qua ineditis efformatus" (Citado por Uriarte-Lecina, 1929, I, p. LXVIII).
} 
los redactados por Francisco Oudin, Juan Luis Courtois y las anotaciones llevadas a cabo por Francisco Antonio Zaccaria, Lorenzo Hervás y Panduro, Ramón Diosdado Caballero y Faustino Arévalo y otros bibliógrafos, concibió la idea de llevar adelante tan ingente tarea. Y cuando verificó que ni la primera, ni la segunda edición de los hermanos Backer daban señales de haber consultado tan rico tesoro decidió ordenar y perfeccionar tan insospechados hallazgos para llevar a buen puerto la empresa que venía haciendo agua desde la segunda mitad del siglo XVII.

Habiéndose dedicado con pasión a completar tan inmenso caudal de información, el año 1890, ya había reunido miles de artículos entre los que se contaban algunos centenares de autores totalmente desconocidos. Pero al aparecer el primer tomo de la Bibliothèque de Sommervogel, en 1890, le hizo cambiar de idea y circunscribirse: en lo geográfico, a lo que había sido la antigua Asistencia de España, es decir, España, Perú, Chile, Nuevo Reino de Granada, Quito, Méjico, Paraguay, Filipinas y Cerdeña; en lo temporal, a lo significó la antigua Compañía, es decir, a la que muere tras el Breve Dominus ac Redemptor; y en cuanto a los sujetos a los que de una manera u otra desarrollaron su actividad o parte de ella en la geografía antes mencionada.

Pero metodológicamente diseñó su obra publicando primero un Catálogo (19041916) que descifrara los anónimos y seudónimos de la Compañía de Jesús en España y América y después la Biblioteca.

En cuanto a la estructura distingue con entidad propia las obras anónimas de las seudónimas y en un apéndice se clasifican aquellas que no pueden ser ubicadas en las dos categorías anteriores (Uriarte, 1904, I, p. XVI).

En 1904 apareció el tomo I y de inmediato obtuvo un aplauso general ${ }^{23}$. Pero su autor sólo pudo presenciar la impresión del tomo III (1906); los otros dos restantes fueron preparados para la imprenta por los PP. Enrique del Portillo (1871-1945) (GarcíaCalvo, 2001, IV, p. 3.196) y Mariano Lecina. Con los Suplementos alcanza la cantidad de 6966 entradas. A ellos hay que añadir las "Adiciones y correcciones" (Uriarte, 1916, V, pp. 99-129). En cuanto a los Índices establecen los siguientes: I. Índice alfabético de las primeras palabras con que comienzan los títulos de todas las obras catalogadas (Uriarte, 1916, V, pp. 133-216). II. Índice de las obras consultadas y de algunas otras que forman parte de este Catálogo razonado (Uriarte, 1916, V, pp. 217-421). III. Índice de autores, traductores y editores anónimos (Uriarte, 1916, V, pp. 422-442). IV. Índice de autores seudónimos (Uriarte, 1916, V, pp. 443-476). V. Índice de autores y seudónimos que usaron (Uriarte, 1916, V, pp. 477-506). VI. Índice de todas las obras catalogadas por orden de materias (Uriarte, 1916, V, pp. 507-622). VII. Índice de algunas cosas notables tomadas de las discusiones o notas críticas (Uriarte, 1916, V, p. 631). VIII. Índice de autores refutados en las notas críticas (Uriarte, 1916, V, pp. 629-638). IX. Índice de las imprentas en que se publicaron las obras contenidas en esta Catálogo razonado (Uriarte, 1916, V, pp. 639-652).

Pero sería el P. Mariano Lecina (1854-1934) (Martínez de la Escalera, 2001, III, p. 2.315. Cascon, 1934) el encargado de llevar adelante su obra inconclusa. Prácticamente prepararía los tomos IV y V del Catálogo razonado e iniciaría el sueño de Uriarte de lanzar al público la Biblioteca de escritores de la Compañía de Jesús, una obra de audacia similar, guardando las debidas distancias, a la que Carlos Sommervogel había levantado sobre la universal Compañía de Jesús con su Bibliothèque.

\footnotetext{
${ }^{23}$ Pueden verse las opiniones en el tomo V, pp. XV-XVII.
} 
Lecina venía de ser investigador del equipo fundado en 1894 para publicar los orígenes fundacionales de la Compañía de Jesús a la luz de la nueva crítica histórica y fundamentada en la revisión exhaustiva de las fuentes, grupo que daría a luz la gran serie denominada "Monumenta Historica Societatis Jesu"24.

El generalato del español Luis Martín (1846-1906) (Sanz de Diego, 2001, II, pp. 1.676-1.682) se caracterizó por una vigorización de los estudios históricos en toda la Compañía. Entre las medidas prácticas asumidas, reunió en Roma a los historiadores que debían escribir las historias de las diversas Asistencias: Antonio Astráin (18571928) (Sanz de Diego, 2001, I, pp. 258-259) para España; Alois Kröss (1856-1928) (Szilas, 2001, III, p. 2.228) para la Provincia de Bohemia; Thomas Hughes (1849-1939) (Curran, 2001, II, pp, 1.964-1.965) para Norteamérica; John H. Pollen (1858-1925) (Caraman, 2001, IV, pp. 3.172-3.173) para Inglaterra; Bernhard Duhr (1852-1930) (Schatz, 1001, II, pp. 1.165-1.166) para los países de lengua alemana; Henry Fouqueray (18601927) (Beylard, 1001, II, p. 1.494) para Francia; Pietro Tacchi Venturi (1861-1956) (Martin, 2001, IV, pp. 3.684-3.686) y otros más. Todos ellos fueron instruidos en las nuevas formas históricas por el jesuita teutón Franz Ehrle (1845-1934) (Gerlich, 2001, II, pp. 1.221-1.223), Prefecto de la Biblioteca vaticana y posteriormente cardenal.

En este contexto Mariano Lecina edita en 1914 el IV tomo del Catálogo razonado con la ayuda del P. Enrique Portillo (Uriarte, 1916, IV, pp. V-VI) y en 1916 el tomo $\mathrm{V}$, cosecha casi exclusiva de su trabajo (Uriarte, 1916, V, p. V).

En 1925 lanzaba a la luz pública el primer tomo de la esperada Biblioteca.

En su parco prefacio "al lector" asienta que la Biblioteca constituye el tomo VI de la obra iniciada por el P. José Eugenio de Uriarte y por ende no debe ser divorciada del Catálogo razonado. Asimismo advierte que ha sido prolijo su trabajo pues su antecesor poseía una muy débil información sobre América latina y gran parte del resto de los materiales quedaron "hacinados y sin ordenar" (Uriarte-Lecina, 1925, I, p. V).

La Biblioteca está diseñada para comprender dos grandes partes. En la primera se incluyen los escritores de quienes se conoce algún trabajo impreso y en la segunda los escritores de quienes sólo se tienen noticias de sus manuscritos. Por ello, al final de cada tomo incluye un apéndice que intitula: "Catálogo de los escritores de quienes nada se ha impreso hasta el presente, los cuales reservamos para la segunda parte" ${ }^{25}$.

Para corroborar el valor del aporte que supone su Biblioteca en relación con la de Sommervogel afirma que sólo en la letra A, entre los que se publican en la primera parte y los reseñados en la segunda, "pasa de cuatrocientos treinta el número registrados por nosotros y no mencionados en la Bibliothèque". De igual manera resalta las mejoras introducidas en las notas biográficas dedicadas a cada autor pues ha tenido que consultar centenares de cartas necrológicas y los catálogos trienales de cada una de las Provincias (Uriarte-Lecina, 1925, I, p. VI).

Lamentablemente la muerte le sorprendió en Comillas (Cantabria), el 8 de abril de 1934, cuando preparaba el III tomo de su gran obra (Cascón, 1934, p. 8) ${ }^{26}$. Sus archi-

\footnotetext{
${ }^{24}$ Una breve información sobre Monumenta Historica puede verse en: Zubillaga-Hanich, 1971. Es interesante para el lector conocer la "Breve noticia histórica de la Colección MHSI" (pp. 9*-18*).

${ }^{25}$ En el tomo I, este apéndice corre de la página 617 a la 623. Y en el II, de la página 601-608.

26 "El tomo III que últimamente estaba preparando lo deja bastante incompleto sobre todo en la parte de América, si bien había recorrido los ocho tomos de la Biblioteca Hispano americana de José Toribio
} 
vos, después de diversas vicisitudes tras la expulsión de la Compañía de Jesús de España en 1934, reposan en la Universidad de Comillas de Madrid y sistemáticamente son mejorados por el infatigable y sabio investigador José Martínez de la Escalera.

\section{La historiografía iberoamericana}

Pero de la misma forma que la Biblioteca de la Compañía de Jesús elaborada por Carlos Sommervogel era impensable en pleno siglo XX, opinamos que en tierras americanas se juzgó de igual manera irrealizable el proyecto Uriarte-Lecina. Y a decir verdad la "dispersión" que vivió la Orden fundada por Ignacio de Loyola tras la expatriación de sus miembros de América en 1767 y el cierre legal de la Compañía en 1773, obligaron a las diversas provincias americanas a buscar ámbitos de supervivencia y a perpetuar la memoria de los hombres que supieron dar respuesta al sueño americano.

La expulsión de 1767 significó, desde el punto de vista documental, un momento privilegiado para conocer los archivos y bibliotecas de los miembros de la Compañía de Jesús que laboraban en el continente, pero lamentablemente muchos de esos documentos se dispersaron y extraviaron con gran perjuicio para su estudio (Matteos, 1967, pp.V-LXXXII). Y la restauración fue mucho más tortuosa en tierras americanas que en las españolas. Esa es una razón para entender lo tardío que despiertan las provincias americanas jesuíticas al reto de su pasado histórico plasmado en sus bibliografías.

Por ello no es de extrañar que eruditos estudiosos de la historia de la cultura y de las ideas hispanoamericanas hayan incursionado el campo colonial a fin de poder interpretar correctamente los movimientos intelectuales que se fueron dando en el continente tras la independencia de España.

Un elemento singular es la presencia de jesuitas extranjeros, fundamentalmente alemanes, austriacos, bohemios, italianos, franceses, belgas, irlandeses y centroeuropeos. Ello explica que algunas naciones del viejo mundo hayan adelantado estudios sobre sus connacionales, los cuales ilustran los caminos del investigador en la recolección de ciertos datos biográficos y bibliográficos difíciles de conseguir.

Pero el primero en afrontar el tema de forma autónoma fue el erudito investigador don José Toribio Medina (1914), gran conocedor de la historia hispanoamericana colonial, quien dejó unas Noticias bio-bibliográficas de los jesuitas expulsos, de gran interés para los bibliófilos que estudian la Compañía de Jesús americana. Preocupado por la producción intelectual de los súbditos de la corona hispana desterrados en Italia, siguió los pasos de la obra de Francisco Gustá, de Luis Rizzi y de Diosdado Caballero y esta curiosidad -confiesa- venía desde que escribió sus seis tomos de la Biblioteca hispano-americana (1900-1908) y sintió una necesidad más acuciante tras la publicación de La imprenta en América. (Medina, 1914, p. VII).

La Provincia mexicana fue rica en experiencias biográficas y bibliográficas. Empezamos con Juan Luis Maneiro (1744-1802) (Burrus-Gómez, 2001, III, pp. 2.493. Sommervogel, 1890, V, pp. 473-474. Zambrano y Gutiérrez Casillas, 1977, pp. 98-99), autor de excelentes biografías, en latín, de mexicanos ilustres. Su principal obra: De Vitis aliquot mexicanorum... y de ella afirmará Burrus: "su prosa latina aúna el señorío de los humanistas del Renacimiento con la agilidad y frescura del joven pueblo ameri-

Medina y dejaba anotadas las obras de 38 autores, que comprendían desde FUENTE, Andrés de la, hasta QUIROGA, José”. 
cano" y con ese telón de fondo entablará una polémica con el literato, jesuita italiano, Giovanni Roberti (1719-1786) (Zanfredini, 2001, IV, p. 3.378) quien sostenía que solo los nacidos en Italia eran capaces de dominar el latín (Burrus y Gómez Fregoso, 2001, III, p. 2.493). Este libro, aparecido en Bolonia entre 1791 y 1792, consta de 1.148 páginas y contiene 35 biografías de las que 26 están redactadas in extenso y 9 son breves. A ellas hay que añadir las de Antonio López del Portillo, Pedro Malo y Miguel Gutiérrez lo que nos da un total de 38 biografías ${ }^{27}$ de jesuitas novohispanos que fallecieron en el destierro de Italia.

También hay que hacer alusión a varios escritos redactados sobre otros mexicanos (Osorio Romero, 1988, pp. 35-36) pero el más importante es el de las Memorias (Zambrano y Gutiérrez Casillas, 1977, p. 523) ${ }^{28}$ del P. José Félix Sebastián (1736-1815) (Zambrano y Gutiérrez Casillas, 1977, XVI, p. 523) que en dos tomos se conserva manuscrito en la ciudad de Bolonia, el cual proporciona las biografías de los fallecidos entre 1767 y 1796 (Osorio Romero, 1988, p. 36).

Fuente obligada de consulta para los jesuitas expulsos sigue siendo el Catálogo ${ }^{29}$ del P. Rafael José Zelis (1747-1798) (Zubillaga, 2001, IV, p. 4.074. Sommervogel, 1890, VIII, p. 1.485 y Zambrano-Gutiérrez Casillas, 1977, XVI, pp. 679-680), aumentado por el erudito y polígrafo Pedro Márquez (1741-1820) Gutiérrez y Gómez Fregoso, 2001, III, pp. 2.514-2.516. Sommervogel, 1890, V, pp. 603-605 y Gutiérrez Casillas, 1952, p. 359) y publicado por el P. Andrés Artola en México en 1871.

Fuente también inapreciable, según el testimonio de Francisco Zambrano, es el del cronista Antonio López de Priego (1730-1802) quien se muestra "notable historiador y literato" (Zubillaga, 2001, IV, p. 3.230) sobre todo por la Relación que envía a su hermana, religiosa del convento de Santa Catalina de Puebla, sobre lo acaecido a los expulsos desde el día de su arresto hasta el 1 de octubre de $1785^{30}$.

Pero quien ha llevado a cabo la primera gran síntesis de la bibliografía jesuítica mexicana ha sido el P. Francisco de Paula Zambrano (1888-1973) (Acevez y Gómez Fregoso, 2001, IV, pp. 4.069-4.070) con su obra, en 16 volúmnes, Diccionario biobibliográfico de la Compañía de Jesús en México (Zambrano y Gutiérrez Casillas, 2001, 1961-1977) ${ }^{31}$. Como advierte el autor en su escueto Prólogo, la estructura de cada entrada es la siguiente: La biografía del autor. Las fuentes biográficas por orden alfabético. La bibliografía de cada sujeto y finalmente las referencias bibliográficas (Zambrano, 1961, I, p. 11). Siempre introduce por orden cronológico la rica información biográfica de que dispone. Su ámbito es la Compañía de Jesús que muere en 1773. Nos parece acertado el juicio de sus biógrafos: "Aunque falto de una formación histórico-

\footnotetext{
${ }^{27}$ Para la edición castellana y las ediciones ver Osorio Romero (1988, pp. 30-38).

28 "Del manuscrito autógrafo hay dos ejemplares. El más completo se halla en la Biblioteca del Archigimnasio de Bolonia. En el Arch. Prov. Mex. se encuentra una copia fotográfica”.

${ }^{29}$ Contiene: los sugetos por orden alfabético, por orden de edad, por orden de grado; los colegios, las misiones y los difuntos. Comenzado en Roma por Don Rafael de Zelis el día 27 de Junio, y terminado el 23 de Agosto de 1786. México, 1871.

${ }^{30}$ Carta de un religioso de los extintos jesuitas, a una hermana suya, religiosa del convento de Santa Catarina de la Puebla de los Angeles. Escrita en la ciudad de Bolonia, en $1^{\circ}$ de octubre de 1785. Trata de lo acaecido a estos religiosos desde el día de su arresto, hasta esta fecha, con varias noticias de la Italia y ciudad de Roma. Fue publicada en Cuevas (1944, pp. 15-177).

${ }^{31}$ Desde el tomo al XII los confeccionó el P. Zambrano; desde el XIII al XVI el P. José Gutiérrez Casillas.
} 
técnica, Zambrano fue un historiógrafo nato, de apasionada afición y dedicación. A pesar de sus defectos de nomenclatura y terminología, su obra es una exhaustiva y valiosa mina de información para el historiador". (Acevez y Gómez Fregoso, 2001, IV, p. 4.070)

Una mención muy especial amerita el acucioso trabajo de Bernd Hausberger (1995) sobre los jesuitas centroeuropeos en México. Se trata de una Bio-bibliografía redactada con las exigencias de la metodología moderna y con una concepción muy diversa a la utilizada por Zambrano.

Continuador de la obra de Zambrano para la Compañía de Jesús restaurada es Juan B. Iguíniz con su Bibliografía de los escritores de la provincia mexicana, publicada en $1945^{32}$.

Para el Brasil jesuítico hay que recurrir al historiador Serafim Leite (1890-1969) (Vaz de Carvalho, 2001, III, pp. 2.326-2.327). Prolífico escritor comenzó a preparar en 1933 su monumental História da Companhia de Jesus no Brasil, desde sus orígenes hasta la expulsión de los jesuitas de Brasil por Pombal (1699-1782) (Leite, 2001, I, pp. 672-675) el año 1760 y concluyó su volumen X en $1950^{33}$. Aquí tienen importancia los dos volúmenes dedicados a la bibliografía que consagra a los escritores, aparecidos ambos en $1949^{34}$.

También la gran tercera Provincia jesuítica del Perú ha esbozado sus intentos de Biblioteca. Don Enrique Torres Saldamando editaba en 1882 la obra escrita de los jesuitas peruanos. En años posteriores fue recopilando un nuevo material bibliográfico que generosamente fue remitiendo a su amigo el P. Carlos Sommervogel. Pero el proyecto era mucho más ambicioso pues contemplaba tres grandes series. De la primera acabamos de hablar. Las restantes eran: las de los varones ilustres por sus virtudes y por los servicios prestados a la colonia peruana; las de los admitidos a la hora de la muerte con las de los fundadores, patronos y protectores de las casas y colegios.

La interesante parte de la expulsión y extinción es examinada en algunos aspectos importantes por el P. Rubén Vargas Ugarte en su estudio sobre los Jesuitas peruanos desterrados a Italia ${ }^{35}$.

No todos los países hispanoamericanos han recogido la obra de los jesuitas coloniales y por ello nos remitiremos a una información general que puede ser revisada con detenimiento en la Bibliographie de László Polgár de 1986.

Tal es el caso de Argentina (Polgar, 1986, pp, 22-72) aunque siempre será útil para la consulta biográfica la investigación llevada a cabo por Hugo Storni (1980) sobre los Catálogos de la Provincia del Paraguay, circunscripción jurídica a la que pertenecía Argentina $^{36}$. Idénticas características ofrece el Paraguay pues al fin y al cabo integró la misma Provincia jesuítica (Polgar, 1986, pp. 267-298). A ellas se añade Bolivia (Polgar, 1986, pp. 74-79), Ecuador (Polgar, 1986, pp. 181-186), Panamá (Polgar, 1986, p. 266), Cuba (Polgar, 1986, pp. 178-179) y Uruguay (Polgar, 1986, pp 312-314).

\footnotetext{
${ }^{32}$ Véase: Polgar, 1986, pp. 234-265.

${ }^{33}$ Véase: Polgar, 1986, pp. 80-121.

${ }^{34}$ El volumen VIII recoge los escritores de la $\mathrm{A}$ a la $\mathrm{M}$ y el IX de la $\mathrm{M}$ a la Z. El vol., X es un Índice general.

${ }^{35}$ Véase: Polgar, 1986, pp. 299-310.

${ }^{36}$ A ello hay que añadir del mismo autor las obras publicadas en 1968 (pp, 177-231) y en 1979 (pp. 3-64).
} 
Es una lástima que el P. Walter Hanisch (1972) no pudiera concluir la investigación iniciada con los jesuitas expulsos y extenderla a todo el período colonial como me comunicara su deseo el año 1976. Su estudio se puede enriquecer con los datos de L. Polgár (1986, pp. 157-166).

\section{La historiografía en la Provincia del Nuevo Reino de Granada}

Todo el recorrido que hemos realizado se dirigía a establecer el marco jesuítico de la importancia dada por la Orden de Ignacio de Loyola a las Bibliotecas de escritores pues en esencia se constituye en un inventario de las ciencias cultivadas durante la colonia y una expresión de sus aportes a la cultura neogranadina.

La Provincia del Nuevo Reino de Granada nació en 1604 como Vice-Provincia dependiente del Perú y alcanzó su independencia en 1608. Nuestro propósito se cifra en ofrecer una información precisa sobre los miembros de la Compañía de Jesús que laboraron en tierras neogranadinas desde 1604 hasta 1767.

La única información exclusivamente bibliográfica de que disponemos sobre los escritores neogranadinos fue escrita por Mimbela (1725), titulada Scriptores Provinciae Novi Regni ab anno 1675. Sin embargo, el investigador podrá encontrar una minuciosa información sobre los archivos, historias, autores y documentación jesuítica relativa al Nuevo Reino en nuestro estudio "Fuentes para el estudio de las Misiones jesuíticas en Venezuela (1625-1767)" (Del Rey Fajardo, 1993, pp. 209-399) así como en los diversos trabajos que hemos dedicado a la acción de los seguidores de Ignacio de Loyola en tierras colombianas (2002, 2004a y 2004b).

Como quiera que la Provincia del Nuevo Reino de Granada comprendía las actuales repúblicas de Colombia, Venezuela, República Dominicana y hasta 1696 a Panamá y Ecuador, ya se han elaborado las Bio-bibliografías relativas a Venezuela e Isla de Santo Domingo.

En 1974 publicamos la primera edición de la Bio-bibliografía de los jesuitas en la Venezuela colonial. En esa entrega recogíamos la acción de 268 jesuitas que de forma directa o indirecta habían laborado en las ciudades venezolanas o en la gran Orinoquia. En 1995 salía a la luz pública la segunda edición y su catálogo de personas subió a 318 entradas. Y en la tercera, de próxima aparición, aumentará el número de los jesuitas recensados.

También la Isla de Santo Domingo formó parte integral de la Provincia neogranadina a la vez que fue puerta abierta para las rutas que de la Península buscaban amplias áreas geográficas de Centro, Norte y Sudamérica. La Universidad de Gorjón fue un compromiso serio para las autoridades jesuíticas de Bogotá pues tuvieron que atenderla en el siglo XVIII (Sáez, 1991, I, pp. 175-224). Pero la bio-bibliografía colonial ha sido de forma concienzuda estudiada por José Luis Sáez (1997, pp. 5-156) quien recoge en la primera parte la Isla de Santo Domingo; en la segunda, la isla de Cuba; y en el apéndice: 1) Las vocaciones cubanas y dominicanas que ingresaron y vivieron fuera del Caribe Hispánico (1563-1767); y 2) Expedicionarios que solo se detuvieron en Santo Domingo o Cuba en vía a su destino (1571-1578).

Estos dos aportes constituyen una inapreciable ayuda para la tarea de ofrecer al público lector la visión completa de los escritores jesuitas neogranadinos que dejaron su huella escrita en Colombia. 
Para seguir las huellas de los jesuitas extranjeros que dedicaron su vida a la Provincia del Nuevo Reino hemos consultado los estudios que a continuación indicamos.

Un caso típico lo constituye el interesante libro de Antón Huonder (1899) sobre los jesuitas alemanes que pasaron a Indias aunque haya que ser completado con el Lexicon de Ludwig Koch (1962). En el caso específico de los austriacos puede verse Alexander von Randa (1962) y el Nomenclator biographicus de Ladislaus Lukács (1988).

Nuevas luces sobre los seguidores de Ignacio de Loyola en el ámbito de la "Bélgica antiqua" y sus dependencias mundiales nos las proporciona Willem Audenaert (2000) quien enriquece notablemente el aporte que había iniciado François Kiekens en 1879 (146-152). Para el estudio de algunas personalidades relevantes por sus méritos culturales, científicos o religiosos es preciso acudir a Joseph Masson (1940).

Una guía, aunque incompleta, sobre los italianos expulsos de América en 1767 la presenta Guillermo Kratz (1942, pp, 27-67). Afortunadamente para el Nuevo Reino su lista puede completarse con la levantada por los funcionarios regios hispanos en el Puerto de Santa María conforme iban arribando de América ${ }^{37}$.

En los últimos decenios han sido los historiadores checos quienes se han venido preocupando por la acción de sus antepasados jesuitas en las misiones de América y gracias a la Revista Ibero-Americana Pragensia pueden seguirse esos estudios Kalista para el Nuevo Reino (1968, pp. 153-154) ${ }^{38}$.

Para los súbditos de la corona gala ha sido una pauta consultar la obra en 5 volúmenes del P. Pierre Delattre (1949-1957), aunque para los jesuitas de las Antillas posee una riqueza informativa extraordinaria el Dictionnaire biographique de Bernard David (1984).

Más difícil ha sido estudiar la presencia irlandesa en tierras neogranadinas pues en verdad, fuera de los imprecisos datos ofrecidos por John McErlean (1930, pp. 127138), no nos ha sido fácil identificar nombres de jesuitas que nos consta por los Catálogos del Nuevo Reino que habían nacido en las Islas Británicas (Foley, 1877-1883) ${ }^{39}$.

Una etapa histórica poco estudiada todavía es la relativa al destierro de los miembros de la Provincia del Nuevo Reino en Italia. Un primer intento de descifrar el enigma lo llevó a cabo Juan Manuel Pacheco en sus investigaciones sobre la vida de los jesuitas expulsos y extintos (Pacheco, 1953, pp. 23-78).

De esta forma entregamos a los investigadores e historiadores esta Biblioteca de los escritores jesuitas neogranadinos que juzgamos será de sumo interés para los que estudian el movimiento intelectual y cultural en Colombia y en Latinoamérica.

\section{Referencias bibliográficas}

\section{Archivos}

\footnotetext{
${ }^{37}$ AHN. Jesuitas, 827/2. Filiación de los Regulares de la Compañía del nombre de Jesus pertenecientes a la Provincia de Santa Fee de Bogotá.

${ }^{38}$ También en la misma Revista se encuentran diversos artículos sobre el P. Miguel Alejo Schabel.

${ }^{39}$ En el volumen 7, parte 2, cita a partir de la página 96 un catálogo cronológico de irlandeses entre los que figura el P. Francisco Lea con datos totalmente errados.
} 
AHN (Archivo Histórico Nacional. Madrid). Jesuitas, 827/2. Filiación de los Regulares de la Compañía del nombre de Jesus pertenecientes a la Provincia de Santa Fee de Bogotá.

Archivo de Loyola. Caja, 06, $\mathrm{n}^{\circ} 01$.

\section{Bibliografía}

Acévez, Manuel y Jesús Gómez Fregoso (2001). "Zambrano Berardi, Francisco de Paula”. En: Charles E. O’Neill y Joaquín $\mathrm{M}^{\mathrm{a}}$ Domínguez. Diccionario histórico de la Compañía de Jesús. Biográfico-temático. Roma-Madrid: Institutum Historicum SI-Universidad Pontificia Comillas, IV, pp. 4.069-4.070.

Artola, Andrés (1871). Catálogo de los sugetos de la Compañía de Jesús, que formaban la Provincia de México el dia del arresto, 25 de Junio de 1767. México: Imprenta de I. Escalante.

Artola, Andrés (s/f). Hispani Societatis Jesu Scriptores. Collectore P. Andrea Artola, ejusdem Societatis. Mss. Tres tomos en cuarto. El tomo I lleva al frente: "Specimen Bibliothecae Hispano-Jesuiticae seu Syllabus Hispaniensium S. J. Scriptorum ex variis monumentis qua editis, qua ineditis efformatus".

Astorgano Abajo, Antonio (2004). "La Biblioteca jesuítico-española de Hervás y su liderazgo sobre el resto de los ex jesuitas”. Hispania Sacra. Madrid, 56, pp. 171268.

Audenaert, Willem (2000). Prosopographia iesuitica Bélgica antiqua (PIBA). A biographical dictionary of the jesuits in the Low countries 1542-1773. Introduction by Hermann Morlion. Leuven-Heverlee, Filosofisch en Theologisch College S. J., 4 vols.

Batllori, Miguel (2001). “Andrés y Morell, Juan”. En: Charles E. O’Neill y Joaquín Ma Domínguez. Diccionario histórico de la Compañía de Jesús. Biográficotemático. Roma-Madrid: Institutum Historicum SI-Universidad Pontificia Comillas, I, pp. 163-165.

“Aymerich, Mateo". En: Charles E. O’Neill y Joaquín Mª Domínguez. Diccionario histórico de la Compañía de Jesús. Biográfico-temático. Roma-Madrid: Institutum Historicum SI-Universidad Pontificia Comillas, I, pp. 311-312.

“Gustà, Francisco". En: Charles E. O’Neill y Joaquín Ma Domínguez. Diccionario histórico de la Compañía de Jesús. Biográfico-temático. Roma-Madrid: Institutum Historicum SI-Universidad Pontificia Comillas, II, pp. 1.851-1.852.

“Llampillas (Llampilles, Lampillas), Francisco Javier". En: Charles E. O’Neill y Joaquín $\mathrm{M}^{\mathrm{a}}$ Domínguez. Diccionario histórico de la Compañía de Jesús. Biográfico-temático. Roma-Madrid: Institutum Historicum SIUniversidad Pontificia Comillas, III, p. 2.400.

"Pratdesaba (Prat de Saba), Onofre". En: Charles E. O’Neill y Joaquín Ma Domínguez. Diccionario histórico de la Compañía de Jesús. Biográficotemático. Roma-Madrid: Institutum Historicum SI-Universidad Pontificia Comillas, IV, pp. 3.214-3.215. 
“Serrano, Tomás”. En: Charles E. O’Neill y Joaquín Ma Domínguez. Diccionario histórico de la Compañía de Jesús. Biográfico-temático. Roma-Madrid: Institutum Historicum SI-Universidad Pontificia Comillas, IV, p. 3.560.

(1966). La cultura hispano-italiana de los jesuitas expulsos. Españoleshispanoamericanos-filipinos. Madrid: Editorial Gredos.

Bellettini, Pierangelo (1998). "Tipografi romagnoli et ex gesuiti spagnoli negli ultimi decenni del Settecento". En: Lorenzo Baldacchini y Anna Manfron (Edits.). Il libro in Romagna. Produzione, commercio e consumo dalla fine del secolo XV all'età contemporánea . Convengo di studi (Cesena, 23-25 marzo 1995) a cura di ... Firenze, Leo S. Olschki, pp. 557-657.

Beylard, Hugues (2001). "Fouqueray, Henri”. En: Charles E. O’Neill y Joaquín Ma Domínguez. Diccionario histórico de la Compañía de Jesús. Biográficotemático. Roma-Madrid: Institutum Historicum SI-Universidad Pontificia Comillas, II, p. 1.494.

Burrus, Ernest J. y Jesús Gómez Fregoso (2001). "Maneiro, Juan Luis". En: Charles E. O’Neill y Joaquín $\mathrm{M}^{\mathrm{a}}$ Domínguez. Diccionario histórico de la Compañía de Jesús. Biográfico-temático. Roma-Madrid: Institutum Historicum SIUniversidad Pontificia Comillas, III, p. 2.493.

Caballero, Raymundo Diosdado (1814-1816). Bibliothecae scriptorum Societatis Jesu supplementa. Romae: F. Bourlié, 2 vols.

Cacho, Xavier. “Artola, Andrés”. En: Charles E. O’Neill y Joaquín Mª Domínguez. Diccionario histórico de la Compañía de Jesús. Biográfico-temático. RomaMadrid: Institutum Historicum SI-Universidad Pontificia Comillas, I, p. 255.

Caraman, Philip (2001). "Pollen, John Hungerford”. En: Charles E. O’Neill y Joaquín $\mathrm{M}^{\mathrm{a}}$ Domínguez. Diccionario histórico de la Compañía de Jesús. Biográficotemático. Roma-Madrid: Institutum Historicum SI-Universidad Pontificia Comillas, IV, pp. 3.172-3.173.

Cascón, Miguel (1934). La obra bibliográfica del P. Mariano Lecina. Comillas. (Separata del número 35 de Noticias de la Provincia de León S. I.)

Cuevas, Mariano (1944). "Carta de un religioso de los extintos jesuitas, a una hermana suya, religiosa del convento de Santa Catarina de la Puebla de los Ángeles. Escrita en la ciudad de Bolonia, en $1^{\circ}$ de octubre de 1785". Tesoros documentales de Méxicosiglo XVIII: Priego, Zelis, Clavijero. México, pp. 15-177.

Curran, Francis X. (2001). "Hughes, Thomas Aloysius". En: Charles E. O’Neill y Joaquín $\mathrm{M}^{\mathrm{a}}$ Domínguez. Diccionario histórico de la Compañía de Jesús. Biográfico-temático. Roma-Madrid: Institutum Historicum SI-Universidad Pontificia Comillas, II, pp. 1.964-1.965.

David, Bernard (1984). Dictionnaire biographique de la Martinique (1635-1848). "Le Clergé". Tome I, pp. 1.635-1.715. Fort-de-France, Societé d'Histoire de la Martinique.

De la Campa, Hermenegildo (2001). "Hervás y Panduro, Lorenzo". En: Charles E. O’Neill y Joaquín $\mathrm{M}^{\mathrm{a}}$ Domínguez. Diccionario histórico de la Compañía de Jesús. Biográfico-temático. Roma-Madrid: Institutum Historicum SI - Universidad Pontificia Comillas, II, pp. 1.914-1.916. 
Decorme, Xavier (1916). Historia de la Compañía de Jesús en la República Mexicana durante el siglo XIX. Guadalajara-Chihuahua: Tip. Lit. y Encuad. J. M. Yguiniz.

Del Rey Fajardo SJ, José (1974). Bío-bibliografía de los jesuitas en la Venezuela colonial. Caracas.

(1993). "Introducción al estudio de la Historia de las Misiones jesuíticas en la Orinoquia”. En José Del Rey Fajardo (Edit.). Misiones jesuíticas en la Orinoquia. San Cristóbal, I, pp. 209-399.

(1995). Bio-bibliografía de los Jesuitas en la Venezuela colonial. San Cristóbal-Santafé de Bogotá: Universidad Católica del Táchira-Pontificia Universidad Javeriana.

(2002). Catedráticos jesuitas de la Javeriana colonial. Bogotá: CEJA.

(2004a). Jesuitas, libros y política en el Real Colegio Mayor y Seminario de San Bartolomé. Bogotá: Publicaciones Editores.

(2004b). Los jesuitas en Cartagena de Indias 1604-1767. Bogotá: Pontificia Universidad Javeriana.

Delattre, Pierre (1949-1957). Les établissements des Jésuites en France depuis quatre siècles. Repertoire Topo-Bibliographique publiée á l'occasion du Quatrième Centanaire de la fondation de la Compaganie de Jésus 1540-1940 sous la direction de Pierre Delattre. Enghien-Wetteren, Institut Supérieur de ThélogieImprimerie De Meester Frères, 5 vols.

Domergue, Lucienne (2001). "Les jésuites espagnols écrivaints et l'appareil d'Etat (1767-1808)". En: Manfred Tietz (Edit.). Los jesuitas españoles expulsos. Su imagen y su contribución al saber sobre el mundo hispánico en la Europa del siglo XVIII. Madrid-Frankfurt/M., pp. 265-294.

Fernández Arrillaga, Inmaculada (2002). "Manuscritos sobre la expulsión y el exilio de los jesuitas (1767-1815)". En: Enrique Giménez López (Edit.). Y en el tercero perecerán. Gloria, caída y exilio de los jesuitas españoles en el x. XVIII. Alicante: Universidad de Alicante, pp. 495-511.

Foley, Henry (1877-1883). Records of the English Province of the Society of Jesus. London: Burns and Oates.

Fontdevall [pseud. de Onofre Prat de Saba] (1803). Operum scriptorum Aragonensium olim e Societate Jesu in Italiam deportatorum Index editus in lucem a Josepho Fonito a Valle Ausetano. S. 1. y a. Roma.

García Goldáraz, Carlos (1947). "Vida del P. Bernardo Recio". En: Bernardo Recio. Compendiosa relación de la cristiandad de Quito. Madrid: Consejo Superior de Investigaciones Científicas, pp. 21-45.

García-Calvo, Julián (2001). "Portillo, Enrique del”. En: Charles E. O’Neill y Joaquín $\mathrm{M}^{\mathrm{a}}$ Domínguez. Diccionario histórico de la Compañía de Jesús. Biográficotemático. Roma-Madrid: Institutum Historicum SI - Universidad Pontificia Comillas, IV, p- 3.196.

Gerlich, Robert S. (2001). “Ehrle, Franz”. En: Charles E. O’Neill y Joaquín Ma Domínguez. Diccionario histórico de la Compañía de Jesús. Biográfico-temático. Ro- 
ma-Madrid: Institutum Historicum SI - Universidad Pontificia Comillas, II, pp. 1.221-1.223.

Giménez López, Enrique (Ed.) (1997). Expulsión y exilio de los jesuitas españoles. Alicante: Publicaciones de la Universidad de Alicante.

(Ed.) (2002). Y en el tercero perecerán. Gloria, caída y exilio de los jesuitas españoles en el s. XVIII. Alicante: Universidad de Alicante.

Gutiérrez, Juan y Jesús Gómez Fregoso (2001). "Márquez, Pedro José”. En: Charles E. O’Neill y Joaquín Ma Domínguez. Diccionario histórico de la Compañía de Jesús. Biográfico-temático. Roma-Madrid: Institutum Historicum SI - Universidad Pontificia Comillas, III, pp. 2.514-2.516.

Hanisch, Walter (1972). Itinerario y pensamiento de los jesuitas expulsos de Chile (1767-1815). Santiago de Chile: Editorial Andrés Bello.

Hausberger, Bernd (1995). Jesuiten aus Mitteleuropa im kolonialem Mexico. Eine BioBiblibliographie. Wien-München: Verlag für Geschichte un Politik.

Hervás y Panduro, Lorenzo (2009). Biblioteca jesuítico-española II. Manuscritos hispano-portugueses en siete bibliotecas de Roma. Estudio introductorio, edición crítica y notas: Antonio Astorgano Abajo. Madrid: Libris. Asociación Libreros de viejo.

(178-1792). Idea dell'Universo, che contiene la Storia della vita dell'uomo, elementi cosmografici, viaggio estatico al mondo planetario, e Storia della terra. Cesena, 22 volúmenes. Los tomos XVII-XXI salieron con título separado y son: XVII: Catalogo delle lingue conosciute e noticia della loro afinitá e diversità. 1784. XVIII: Origine, formazione, mecanismo ed armonia degl' idiomi. 1785. XIX: Arithmetica delle Nazioni, e divisione del tempo fra gli Orientali. 1786. XX. Vocabulario poliglotto...,1787. XXI: Saggio prattico delle lingue come prolegomeni e una raccolta di orazioni dominicali in più de trecento lingue et dialecti..., 1787.

Huonder, Anton (1899). Deutsche Jesuitenmissionäre des 17 und 18 Jahrhunderts. Freiburg/B.: Herder'sche Verlagshandlung.

Iguíniz, Juan B. (1945). Bibliografía de los escritores de la provincia mexicana de la Compañía de Jesús, desde su restauración hasta nuestros días. México : Buena Prensa.

Kalista, Zdenek (1968). "Los misioneros de los países checos que en los siglos XVII y XVIII actuaban en América Latina". En: Ibero-Americana Pragensia. Praga, II.

Kiekens, François (1879). "Les enciens missionnaires belges de la Compagnie de Jesús dans les deux Ameriques". Precis historiques, 28, pp. 146-152.

Koch, Ludwig (1962). Jesuiten-Lexicon. Die Gesellschaft Jesu einst und jetzt. LöwenHeverlee: Verlag der Bibliothek SJ, 2 vols.

Kratz, Guillermo (1942). "Gesuiti italiani nelle Messioni spagnuole al tempo dell'espulsione (1767-1768)". Archivum Historicum Societatis Iesu. Roma, 11, pp. 27-67.

Lecina, Mariano (1916). "Breve noticia bio-bibliográfica del P. José Eugenio de Uriarte y Barrenechea, S. J.”. En: P. J. Eug. De Uriarte. Catálogo razonado de obras 
anónimas y seudónimas de autores de la Compañía de Jesús pertenecientes a la antigua asistencia española..., V, pags., XI-XXV.

Leite, António (2001). "Carvalho, Sebastião José de. Pombal (marqués de)". En: Charles E. O’Neill y Joaquín Ma Domínguez. Diccionario histórico de la Compañía de Jesús. Biográfico-temático. Roma-Madrid: Institutum Historicum SI - Universidad Pontificia Comillas, I, pp. 672-675.

Leite, Serafím (1938-1950). História da Companhia de Jesús no Brasil. Lisboa-Río de Janeiro, 1938-1950, 10 vols. Reedición facsimilar Sao Paulo: Edición patrocinada por PETROBRAS, 2004.

Luengo, Manuel. "Diario, sobre el destierro y vicisitudes de la Provincia de Castilla la Viexa, después más en general de toda la Compañía, aunque siempre con mayor particularidad de la dicha Provincia de Castilla”. Manuscrito que reposa en el Archivo de Loyola (Guipúzcoa); consta de 63 tomos (falta el tomo IV correspondiente al año 1770). Ha sido publicado el tomo I por la investigadora de la Universidad de Alicante Inmaculada Fernández Arrillaga.

Lukács, Ladislaus (1988). Catalogus Generalis seu Nomenclator biographicus personarum Provinciae Austriae Societatis Iesu (1551-1773). Romae: Institutum Historicum S.I. II.

Mac Erlean, John (1930). "Irish Jesuits in Foreing Missions from 1574 to 1773". En: Irish Jesuit Directory and Year Book, pp. 127-138.

Maneiro, Juan Luis (1791-1792). Joannes Aloysii Maneiri veracrucensisde Vitis aliquot mexicanorum aliorumque qui sive virtute, sive litteris Mexici imprimis floruerunt. Pars prima, Bononiae, 1791. Pars secunda. Bononiae, 1792. Pars tertia. Bononiae, 1792.

Martina, Giacomo (2001). “Tacchi Venturi, Pietro”. En: Charles E. O’Neill y Joaquín $\mathrm{M}^{\mathrm{a}}$ Domínguez. Diccionario histórico de la Compañía de Jesús. Biográficotemático. Roma-Madrid: Institutum Historicum SI - Universidad Pontificia Comillas, IV, pp. 3.684-3.686.

Martínez de la Escalera, José (1982). “El P. Aymerich y la obra del P. Garzón”. Miscelánea Comillas. Madrid, 40, pp. 283-289.

(2001). "Lecina, Mariano”. En: Charles E. O’Neill y Joaquín Ma Domínguez. Diccionario histórico de la Compañía de Jesús. Biográfico-temático. Roma-Madrid: Institutum Historicum SI - Universidad Pontificia Comillas, III, p. 2.315 .

(2001). “Uriarte, José Eugenio de”. En: Charles E. O’Neill y Joaquín Ma Domínguez. Diccionario histórico de la Compañía de Jesús. Biográficotemático. Roma-Madrid: Institutum Historicum SI - Universidad Pontificia Comillas, IV, p. 3.861.

Masson, Joseph (1947). Missionaires belges sous l'ancien régime (1500-1800). Tome I. Ceux qui verserent leur sang. Bruxelles-Paris: L'Éd. Universelle de Brouwer.

Mateos, Francisco (1967). "El secuestro de papeles jesuíticos en el siglo XVIII, su concentración en Madrid, vicisitudes y estado actual”. En: Araceli Guglieri Navarro. Documentos de la Compañía de Jesús en el Archivo Histórico Nacional. Madrid: Editorial Razón y Fe, pp. V-LXXXII. 
Medina, Francisco de Borja. “Osuna [Ossuna], Juan de”. En: Charles E. O’Neill y Joaquín $\mathrm{M}^{\mathrm{a}}$ Domínguez. Diccionario histórico de la Compañía de Jesús. Biográfico-temático. Roma-Madrid: Institutum Historicum SI - Universidad Pontificia Comillas. III, pp. 2.931-2.932.

Medina, José Toribio (1900-1908). Biblioteca Hispano-Americana (1493-1810) por José Toribio Medina. Santiago de Chile: Impreso y grabado en casa del autor, 6 tomos.

(1914). Noticias bio-bibliográficas de los jesuitas expulsos de América en 1767. Santiago de Chile: Impr. Elzeviriana.

Mimbela, Mateo (1725). Scriptores Provinciae Novi Regni ab anno 1675. Sanctafide in Novo Regno Granatensi, 25 Augusti a. El Manuscrito reposa en la actualidad en el Archivo Uriate-Lecina, en la Universidad de Comillas (Madrid).

Noguer, N. (1916). "Examen de la obra "Catálogo razonado de obras anónimas". Razón y Fe. Madrid, 46, pp. 384-387.

Notizia degli Scrittori Gesuiti, i quali dopo l'abolizione della Compagina hanno publicato diverse opere.

Olaechea, Rafael. "Luengo, Manuel Rodríguez". En: Charles E. O’Neill y Joaquín Mª Domínguez. Diccionario histórico de la Compañía de Jesús. Biográficotemático. Roma-Madrid: Institutum Historicum SI - Universidad Pontificia Comillas. III, p. 2.437.

Osorio Romero, Ignacio (1988). "Estudio introductorio". En: Juan Luis Maneiro. Vida de algunos mexicanos ilustres. Traducción de Alberto Valenzuela Rodarte. Estudio introductorio y apéndice de Ignacio Osorio Romero. México: Universidad Nacional Autónoma de México, pp. 30-38.

Pacheco, Juan Manuel (1953). "Los jesuitas de la Provincia del Nuevo Reino de Granada expulsados en 1767”. Ecclesiastica Xaveriana. Bogotá, 3, pp. 23-78.

Page, Carlos A. (2011). Relatos desde el exilio. Memorias de los jesuitas expulsos de la antigua provincia del Paraguay. Asunción: Servilibro.

Pérez Goyena, Antonio (1909). "Un bibliógrafo insigne”. Razón y Fe. Madrid, 25, pp. 368-373.

Polgar, László (1986). Bibliographie sur l’histoire de la Compagnie de Jesús 1901 1980. II. Les Pays. Roma: Institum Historicum S.I.

Portillo, Enrique del (1912). "Lorenzo Hervás”. Razón y Fe. Madrid, XXXII, p. 18.

Prat de Saba, Onofre (i ?). Annus faustus ex diebus fastis quorumdam illustrium virorum S. J. ab Hispaniensibus regnis exulum.

(1787). Vicennalia sacra Aragoniensia sive de viris Aragoniensibus religione illustribus Hisce Viginti Annis gloriosa morte functis. Ab Onuphrio Prat de Saba Sac. Hispano. Ferrariae.

Randa, Alexander von (1962). "Los jesuitas austriacos en la provincia de Nueva Granada". Tercer Congreso hispanoamericano de Historia. Segundo de Cartagena de Indias. Cartagena de Indias, I, pp. 326-327. 
Recio, Bernardo (1947). “Opúsculo y Catálogo De Los Jesuitas Escritores Naturales De Cataluña... Escrito por el mismo autor En Gerona Año de 1773”: En: Bernardo Recio. Compendiosa relación de la cristiandad de Quito. Madrid: Consejo Superior de Investigaciones Científicas, pp. 215-251.

Sáez, José Luis (1997). "Los jesuitas en el Caribe insular de habla castellana (15751767)". Paramillo. San Cristóbal, 16, pp. 5-156.

(1991). "Universidad Real y Pontificia de Santiago de la Paz y de Gorjón en la Isla Española (1747-1767)". En: José Del Rey Fajardo (Edit.). La pedagogía jesuítica en Venezuela. San Cristóbal, I, pp. 175-224.

Sanz de Diego, Rafael M. (2001). “Astrain, Antonio”. En: Charles E. O’Neill y Joaquín Ma Domínguez. Diccionario histórico de la Compañía de Jesús. Biográficotemático. Roma-Madrid: Institutum Historicum SI - Universidad Pontificia Comillas, I, pp. 258-259.

(2001). "Martín García, Luis". En: Charles E. O’Neill y Joaquín M ${ }^{a}$ Domínguez. Diccionario histórico de la Compañía de Jesús. Biográficotemático. Roma-Madrid: Institutum Historicum SI - Universidad Pontificia Comillas, II, pp. 1.676-1.682.

Schatz, Klaus (2001). "Duhr, Bernhard”. En: Charles E. O’Neill y Joaquín Ma Domínguez. Diccionario histórico de la Compañía de Jesús. Biográfico-temático. Roma-Madrid: Institutum Historicum SI - Universidad Pontificia Comillas, II, pp. 1.165-1.166.

Sebastián, Félix, Memorias de los Padres y hermanos de la Compañía de Jesús de la Provincia de Nueva España, Difuntos después del arresto acaecido en la Capital de México el día 25 de junio de 1767. Escritas por Feliz de Sebastián Sacerdote de la misma Provincia Misionero que era de la Nación Tubara. (Mss.)

Sommervogel, Carlos (1890-1932). Bibliothèque de la Compagnie de Jésus. Bruxelles, Schepens-París, Picard, 11 vols. [Reimpresión por el P. M. DYKMANS. Héverlé-Louvain. Éditions de la Bibliothèque S. J. Collège philosophique et théologique, 1960].

Storni, Hugo (1968). "Los jesuitas argentinos expulsos (1767-1830). En: Anales de la Universidad del Salvador. Buenos Aires, 4, pp. 177-231.

(1979). "Jesuitas italianos en el Río de la Plata (antigua Provincia del Paraguay, 1585-1768)”. Archivum historicum Societatis Iesu. Roma, 48, pp. 3-64.

(1980). Catálogo de los jesuitas de la Provincia del Paraguay (Cuenca del Plata), 1585-1768. Roma; Institutum Historicum S. I.

Szilas, László. “Kröss, Alois”. En: Charles E. O’Neill y Joaquín Ma Domínguez. Diccionario histórico de la Compañía de Jesús. Biográfico-temático. Roma-Madrid: Institutum Historicum SI - Universidad Pontificia Comillas, III, p. 2.228.

Tietz, Manfred (Edit.) (2001). Los jesuitas españoles expulsos. Su imagen y su contribución al saber sobre el mundo hispánico en la Europa del siglo XVIII. Madrid: Iberoamericana; Frankfurt am Main: Vervuert.

Torres Saldamando, Enrique (1882). Los antiguos jesuitas del Perú. Biografías y apuntes para su Historia. Lima: Imprenta Liberal. 
Uriarte, José Eugenio y Lecina, Mariano (1929). Biblioteca de escritores de la Compañía de Jesús pertenecientes a la antigua Asistencia de España. Tomo I. Madrid: Imprenta Gráfica Universal.

Uriarte, José Eugenio (1904-1916). Catálogo razonado de obras anónimas y seudónimas de autores de la Compañía de Jesús pertenecientes a la antigua asistencia española: con un apéndice de otras de los mismos, dignas de especial estudio bibliográfico... Madrid, Sucesores de Rivadeneyra, 5 vols.

Vargas Ugarte, Rubén (1934). Jesuitas peruanos desterrados a Italia. Lima: La Prensa (Empresa Periodística).

Vaz de Carvalho, José. "Leite, Serafim”. En: Charles E. O’Neill y Joaquín Ma Domínguez. Diccionario histórico de la Compañía de Jesús. Biográfico-temático. Roma-Madrid: Institutum Historicum SI - Universidad Pontificia Comillas, III, pp. 2.326-2.327.

Villalba, Jorge. "Recio, Bernardo". En: Charles E. O’Neill y Joaquín Ma Domínguez. Diccionario histórico de la Compañía de Jesús. Biográfico-temático. RomaMadrid: Institutum Historicum SI - Universidad Pontificia Comillas, IV, p. 3.304.

Zambrano, Francisco y José Gutiérrez Casillas (1961-1977). Diccionario biobibliográfico de la Compañía de Jesús en México. México: Edit. Jus, 16 vols.

Zanfredini, Mario (2001). "Bettinelli, Saverio". En: Charles E. O’Neill y Joaquín Ma Domínguez. Diccionario histórico de la Compañía de Jesús. Biográficotemático. Roma-Madrid: Institutum Historicum SI - Universidad Pontificia Comillas, I, p. 432.

(2001). "Roberti, Giovanni Battista". En: Charles E. O’Neill y Joaquín Ma Domínguez. Diccionario histórico de la Compañía de Jesús. Biográficotemático. Roma-Madrid: Institutum Historicum SI - Universidad Pontificia Comillas, IV, p. 3.378.

(2001). "Tiraboschi, Girolamo". En: Charles E. O’Neill y Joaquín Ma Domínguez. Diccionario histórico de la Compañía de Jesús. Biográficotemático. Roma-Madrid: Institutum Historicum SI - Universidad Pontificia Comillas, IV, pp. 3.804-3.805.

Zelis, Rafael (1871). Catalogo de los sugetos de la Compañía de Jesús, que formaban la Provincia de México el día del arresto, 25 de Junio de 1767. Contiene: los sugetos por orden alfabético, por orden de edad, por orden de grado; los colegios, las misiones y los difuntos. Comenzado en Roma por Don Rafael de Zelis el día 27 de Junio, y terminado el 23 de Agosto de 1786. México: Impr. de I. Escalante.

Zubillaga, Félix-Walter Hanisch (1971). Guía manual de los documentos históricos de la Compañía de Jesús de los cien primeros volúmenes, que tratan de los orígenes de la Compañía, de San Ignacio, de sus compañeros y colaboradores, legislación, pedagogía y Misiones de Asia y América. Romae.

Zubillaga, Félix (2001). “Priego, Antonio López de”. En: Charles E. O’Neill y Joaquín $\mathrm{M}^{\mathrm{a}}$ Domínguez. Diccionario histórico de la Compañía de Jesús. Biográficotemático. Roma-Madrid: Institutum Historicum SI - Universidad Pontificia Comillas, IV, p. 3.230. 
(2001). "Zelis, Rafael José de”. En: Charles E. O’Neill y Joaquín Ma Domínguez. Diccionario histórico de la Compañía de Jesús. Biográficotemático. Roma-Madrid: Institutum Historicum SI - Universidad Pontificia Comillas, IV, p. 4.074. 